\title{
Evidence for a Parathyroid Hormone-Dependent Influence of Calcium on the
}

\section{Glomerular Ultrafiltration Coefficient}

\author{
H. David Humes, Iekuni IChikawa, Julia L. Troy, and BarRy M. Brenner, \\ Laboratory of Kidney and Electrolyte Physiology and Departments \\ of Medicine, Peter Bent Brigham Hospital and Harvard Medical \\ School, Boston, Massachusetts 02115
}

A B S T RACT Experiments were performed on 36 plasma-expanded Munich-Wistar rats to examine the effects of acute hypercalcemia on the determinants of glomerular ultrafiltration. Elevation of total plasma calcium concentration to an average value of $13.2 \pm 0.5$ $\mathrm{mg} / \mathrm{dl}$, by acute infusion of calcium chloride into nonthyroparathyroidectomized (non-TPTX) rats, resulted in significant declines in single nephron and whole kidney glomerular filtration rate. These declines were due primarily to a fall in the glomerular capillary ultrafiltration coefficient $\left(K_{f}\right)$, to a mean value approximately $60 \%$ below that determined in the preinfusion period. These changes were not seen in a separate group of sham-treated non-TPTX rats.

It is of interest that these effects of acute hypercalcemia were largely abolished in rats that underwent acute TPTX before hypercalcemia. Infusion of a submaximally phosphaturic dose of parathyroid hormone, together with calcium chloride, into a second group of acute TPTX rats, however, had the effect of reproducing the striking declines in filtration rate and $K_{f}$ noted in non-TPTX rats given calcium chloride alone. These findings suggest that the decline in filtration rate associated with hypercalcemia is due largely to the reduction in $K_{f}$, the latter dependent upon the presence of parathyroid hormone.

Portions of these studies were presented at the annual meeting of the Association of American Physicians, Washington, D. C., 1 May 1977, and published in abstract form in 1977. Clin. Res. 25: 526A. (Abstr.)

Dr. Humes has an Institutional National Research Service Award from the National Institutes of Health (NHLBI no. 07066). Dr. Ichikawa is a Postdoctoral Research Fellow in the Laboratory of Kidney and Electrolyte Physiology, Peter Bent Brigham Hospital.

Received for publication 11 July 1977 and in revised form 6 September 1977.

\section{INTRODUCTION}

Antidiuretic hormone (ADH) and parathyroid hormone (PTH), peptides known to increase cyclic nucleotide production in isolated glomeruli $(1,2)$, have recently been found to reduce the glomerular capillary ultrafiltration coefficient $\left(K_{f}\right)$ in the Munich-Wistar rat $(3,4)$. Furthermore, prostaglandin $\mathrm{E}_{1}\left(\mathrm{PGE}_{1}\right)$ has also been shown to reduce $K_{f}$ in this strain of rats (5). Because prostaglandins of the $\mathrm{E}$ series are also known to stimulate cAMP production in isolated glomeruli, ${ }^{1}$ and because dibutyryl cAMP (DBcAMP) has also been found to reduce $K_{f}$ in vivo (3), these results suggest that the effects of $\mathrm{ADH}, \mathrm{PTH}$, and $\mathrm{PGE}_{1}$ to reduce $K_{f}$ are secondary to some as yet unidentified glomerular action of cyclic nucleotides.

The calcium ion appears to be intimately involved in the intracellular action of cyclic nucleotides, serving as an important regulator of cAMP-mediated effects in several mammalian cell systems (6), including renal tubule epithelial cells $(7,8)$. In addition, the calcium ion is capable of stimulating production of cGMP in several tissues (9), again including renal epithelia (10). Because elevation in plasma calcium concentration is well known to diminish glomerular filtration rate (GFR; 11-13), and because the calcium ion exerts a potent influence on cyclic nucleotide production and action, we undertook the present series of investigations to explore the effects of acute hypercalcemia on the determinants of GFR.

\section{GLOSSARY OF SYMBOLS}

$\overline{\mathbf{A P}}$ Mean femoral arterial pressure, $\mathrm{mm} \mathrm{Hg}$.

ADH Antidiuretic hormone.

C Protein concentration, $\mathrm{g} / \mathrm{dl}$.

${ }^{1}$ Schlondorff, D. Unpublished observations. 
cAMP Adenosine-3',5'-cyclic monophosphate.

cGMP Guanosine-3',5'-cyclic monophosphate.

DBcAMP Dibutyryl cAMP.

$\mathrm{FE}_{\mathrm{p}}$ Fractional excretion of phosphate (phosphate clearance/inulin clearance) $\times 100$.

GFR Glomerular filtration rate (whole kidney), $\mathrm{ml} / \mathrm{min}$.

Het Blood hematocrit in femoral artery, vol \%.

k Effective hydraulic permeability, $\mathrm{nl} /(\mathrm{s} \cdot \mathrm{mm} \mathrm{Hg}$. $\mathrm{cm}^{2}$ ).

$\mathrm{K}_{\mathrm{f}}$ Ultrafiltration coefficient, $\mathrm{nl} /(\mathrm{s} \cdot \mathrm{mm} \mathrm{Hg})$.

$\mathrm{P}$ Hydraulic pressure, $\mathrm{mm} \mathbf{H g}$.

$P_{C a}$ Total plasma calcium concentration, $\mathrm{mg} / \mathrm{dl}$.

$\mathrm{PGE}_{1}$ Prostaglandin $\mathrm{E}_{1}$.

PTH Parathyroid hormone.

$\Delta \mathbf{P}$ Transcapillary hydraulic pressure difference, $\mathbf{P}_{\mathrm{GC}}-\mathbf{P}_{\mathrm{T}}, \mathbf{m m} \mathbf{H g}$.

ПI Colloid osmotic pressure, $\mathrm{mm} \mathrm{Hg}$.

$\Delta \Pi$ Colloid osmotic pressure difference, $\Pi_{G C}-\Pi_{T}$, $\mathrm{mm} \mathrm{Hg}$.

$\mathrm{Q}_{\mathrm{A}}$ Initial glomerular capillary plasma flow rate, $\mathrm{nl} / \mathrm{min}$.

S Surface area per glomerulus available for ultrafiltration, $\mathrm{cm}^{2}$.

SNFF Single nephron filtration fraction.

SNGFR Single nephron glomerular filtration rate, $\mathrm{nl} / \mathrm{min}$.

$(\mathrm{TF} / \mathrm{P})_{\text {In }}$ Tubule fluid to plasma inulin concentration ratio.

TPTX Thyroparathyroidectomy.

$\mathrm{V}_{\mathrm{TF}}$ Tubule fluid flow rate, $\mathrm{nl} / \mathrm{min}$.

\section{Superscript}

- Mean value.

A Afferent arteriole.

C Peritubular capillary.

E Efferent arteriole.

GC Glomerular capillary.

T Proximal tubule.

\section{METHODS}

General. Studies were performed in 36 adult male Munich-Wistar rats, weighing 214-271 g. Before the study, animals were allowed free access to a regular pellet diet and water. Rats were anesthetized with Inactin $(100 \mathrm{mg} / \mathrm{kg}$, i.p.), placed on a temperature-regulated micropuncture table, and subjected to tracheostomy. Polyethylene catheters were inserted into the left jugular vein for infusion of inulin and PTH solution, into the right jugular vein for infusion of calcium chloride or sodium chloride solutions, into the left femoral vein for infusion of iso-oncotic plasma, and into the left femoral artery for periodic blood sampling and estimation of mean femoral arterial pressure, $(\overline{\mathrm{AP}})$. $\overline{\mathrm{AP}}$ was monitored with an electronic transducer (model P23Db, Statham Instruments Div., Gould Inc., Oxnard, Calif.) connected to a direct-writing recorder (model 7754A, HewlettPackard Co., Palo Alto, Calif.). To achieve initial glomerular plasma flow rates high enough to prevent achievement of filtration pressure equilibrium (defined below), all rats underwent modest plasma volume expansion. A volume of homologous rat plasma (obtained at the time of study by exsanguination of a littermate) equal to $3 \%$ of body wt was infused intravenously. Simultaneously, a volume equivalent to $1.5 \%$ body wt of whole blood was withdrawn from the femoral arterial catheter. The total duration of this hypervolemic exchange was $60 \mathrm{~min}$. This volume-expanded state was maintained with a continuous plasma infusion delivering a volume equivalent to $0.5 \%$ body wt/hr. The left kidney was exposed by a left subcostal incision and gently separated from the adrenal gland and the surrounding perirenal fat. The kidney was suspended on a Lucite holder, and its surface illuminated with a fiber-optic light source and bathed with isotonic $\mathrm{NaCl}$ heated to $35-37^{\circ} \mathrm{C}$. An intravenous infusion of inulin in $\sim 0.8 \% \mathrm{NaCl}$, given at a rate of $0.02 \mathrm{ml} / \mathrm{min}$, was begun at least $60 \mathrm{~min}$ before study, and resulted in final plasma inulin concentrations of about $100 \mathrm{mg} / \mathrm{dl}$.

Micropuncture measurements in all rats were carried out as follows: exactly timed (1-2 min) samples of fluid were collected from a surface proximal convolution from each of 2-3 nephrons for determination of flow rate and inulin concentration and calculation of single nephron glomerular filtration rate (SNGFR). Coincident with these tubule fluid collections, two or three samples of femoral arterial blood were obtained in each period for determination of systemic arterial hematocrit (Hct) and plasma concentrations of protein, inulin, total calcium $\left(\mathrm{P}_{\mathrm{Ca}}\right)$, and phosphate. In addition, two or three samples of urine from the experimental kidney were collected for determination of flow rate, concentrations of inulin and phosphate, and calculation of total kidney GFR and fractional excretion of phosphate $\left(\mathrm{FE}_{\mathrm{p}}\right)$. For these urine collections, indwelling ureteral polyethylene catheters (PE-50 or PE-10) were used. Time-averaged hydraulic pressures were measured in surface glomerular capillaries $\left(\overline{\mathrm{P}}_{\mathrm{GC}}\right)$, proximal tubules $\left(\mathrm{P}_{\mathrm{T}}\right)$, and third-order branch peritubular capillaries $\left(\mathbf{P}_{\mathrm{C}}\right)$, using a continuous recording, servonull micropipette transducer system (model 3, Instrumentation for Physiology and Medicine, San Diego, Calif.). Micropipettes with outer tip diameters of $2-3 \mu \mathrm{m}$ and containing $2.0 \mathrm{M} \mathrm{NaCl}$ were used. Hydraulic output from the servo system was coupled electronically to a second channel of the Hewlett-Packard recorder by means of a pressure transducer.

To estimate the colloid osmotic pressure of plasma entering and leaving glomerular capillaries, protein concentrations $(C)$ in femoral arterial $\left(C_{A}\right)$ and surface efferent arteriolar $\left(\mathrm{C}_{\mathrm{E}}\right)$ blood plasmas were measured as described previously (14). Colloid osmotic pressure (П) was calculated according to the equation derived by Deen et al. (15). Values for $C_{A}$, and thus $\Pi_{A}$, for femoral arterial plasma are taken as representative of values of $C$ and $\Pi$ for the afferent end of the glomerular capillary network. These estimates of pre- and postglomerular protein concentration permit calculation of single nephron filtration fraction (SNFF) and initial glomerular capillary plasma flow rate $\left(Q_{A}\right)$, using equations given below.

Experimental groups 1 and 2. The effects of acute hypercalcemia on glomerular dynamics were studied in seven Munich-Wistar rats (group 2). After hypervolemic exchange transfusion, collections of tubule fluid, urine, efferent arteriolar and femoral arterial blood, and measurements of $\overline{\mathbf{A P}}, \overline{\mathbf{P}}_{\mathrm{GC}}$, and $P_{T}$ were begun and completed in the subsequent $45-\mathrm{min}$ interval. At the end of this initial study period, an infusion of calcium chloride ( $120 \mathrm{mg}$ of elemental calcium per deciliter dissolved in $5 \%$ dextrose solution) was begun at the rate of $0.027 \mathrm{ml} / 100 \mathrm{~g}$ body $\mathrm{wt} / \mathrm{min}$. Within $60 \mathrm{~min}$ a total calcium plasma concentration between 12 and $15 \mathrm{mg} / \mathrm{dl}$ was achieved and the above described measurements and collections were repeated in the subsequent $45 \mathrm{~min}$.

To serve as the control group for this experiment, seven other Munich-Wistar rats (group 1) were studied with an identical protocol except that the calcium chloride solution was replaced by an equimolar solution of sodium chloride. The time-course for collection of fluids and measurements of pressures for both study periods was exactly as that for group 2.

Experimental groups 3 and 4. PTH-dependent cyclic nucleotide production in renal tubule epithelial cells has been 
shown to be enhanced by the addition of calcium ions to the incubation medium (2). Even though circulating PTH levels would be expected to fall with acute hypercalcemia, these recent findings raise the possibility that at least some PTH must be present in order to elicit the hypercalcemiarelated decline in GFR. To test this possibility, seven additional rats (group 3) were acutely thyroparathyroidectomized (TPTX) by electrocautery immediately after induction of anesthesia. Because it is known that circulating endogenous PTH levels are reduced to very low levels within $2 \mathrm{~h}$ after acute TPTX (16), the first study period was carried out 120-150 min after TPTX, and in identical fashion to those in groups 1 and 2 . After completion of the initial study period, the same acute hypercalcemia protocol as employed in group 2 was carried out.

To ascertain whether the failure for GFR to decline with hypercalcemia in TPTX rats was the consequence of deficiency of PTH per se, seven additional TPTX rats (group 4) were studied, using an identical protocol as in group 3 except that PTH was infused in the second study period. Four of the seven rats received $15 \mathrm{U} / \mathrm{kg}$ of synthetic bovine $1-34$ fragment PTH (Beckman Instruments, Inc., Spinco Div., Palo Alto, Calif.) intravenously as a priming infusion, and this hormone was added to the inulin infusion solution to deliver $0.5 \mathrm{U} / \mathrm{kg}$ per min for the duration of the second period. Three of the seven rats received $20 \mathrm{U} / \mathrm{kg}$ of $\mathrm{PTH}$ as a priming infusion followed by a continuous PTH infusion of $0.67 \mathrm{U} / \mathrm{kg}$ per min. In addition to measurement of $P_{C a}$, four groups of two rats each were prepared exactly as rats in groups 1-4, to permit determination of serum ultrafilterable calcium concentrations. $4 \mathrm{ml}$ of blood was collected from each rat in each group at the termination of the second study period.

Analytical. The volume of fluid collected from individual proximal tubules was estimated from the length of the fluid column in a constant bore capillary tube of known internal diameter. The concentration of inulin in tubule fluid was measured, usually in duplicate, by the microfluorescence method of Vurek and Pegram (17). Inulin concentrations in plasma and urine were determined by the macroanthrone method of Führ et al. (18). Protein concentrations in efferent arteriolar and femoral arterial blood plasmas were determined, usually in duplicate, with an ultramicrocolorimeter by using a microadaptation (14) of the method of Lowry et al. (19). Phosphate concentrations in urine and plasma were determined by a modification of the method of Fiske and Subbarow (20). $\mathbf{P}_{\mathrm{Ca}}$ was measured with a Fiske Calcimeter (model TI6009, Fiske Associates, Inc., Uxbridge, Mass.). Ultrafilterable serum calcium concentration was determined by ultrafiltration of $2 \mathrm{ml}$ of serum with a Millipore 25- $\mathrm{mm}$ stirred cell system (Millipore Corp., Bedford, Mass.) and a PM30 Amicon membrane (Amicon Corp., Lexington, Mass.). Measurement of calcium concentration in the initial $300 \mu \mathrm{l}$ of ultrafiltrate was performed with the Fiske Calcimeter.

Calculations. Single nephron glomerular filtration rate:

$$
\mathrm{SNGFR}=(\mathrm{TF} / \mathrm{P})_{\text {In }} \cdot \mathrm{V}_{\mathrm{TF}}
$$

where $(T F / P)_{\text {In }}$ and $V_{T F}$ refer to transtubular inulin concentration ratio and tubule fluid flow rate, respectively.

Single nephron filtration fraction:

$$
\mathrm{SNFF}=1-\frac{\mathrm{C}_{\mathrm{A}}}{\mathrm{C}_{\mathrm{E}}}
$$

where $C_{A}$ and $C_{E}$ denote afferent and efferent arteriolar protein concentrations, respectively.

Initial glomerular capillary plasma flow rate:

$$
\mathrm{Q}_{\mathrm{A}}=\frac{\text { SNGFR }}{\text { SNFF }}
$$

According to the Starling relationship, the rate of ultrafiltration per glomerulus (SNGFR) is given by the expression:

$$
\begin{aligned}
\text { SNGFR } & =K_{\mathbf{f}}(\overline{\Delta \mathbf{P}}-\overline{\Delta \bar{\Pi}}) \\
& =\mathrm{k} \cdot \mathrm{S} \cdot\left[\left(\overline{\mathbf{P}}_{\mathrm{GC}}-\mathrm{P}_{\mathrm{T}}\right)-\left(\bar{\Pi}_{\mathrm{GC}}-\Pi_{\mathrm{T}}\right)\right]
\end{aligned}
$$

The ultrafiltration coefficient $\left(K_{f}\right)$, the product of surface area (S) and effective hydraulic permeability $(k)$ of the filtering capillaries, is calculated from equation 4 and a differential equation which gives the rate of change of protein concentration with distance along an idealized glomerular capillary. Solution of this differential equation, described elsewhere (15), permits calculation of $K_{f}$.

Statistical analyses were performed by the paired $t$ test. Statistical significance is defined as $P<0.05$.

\section{RESULTS}

Initial study period in groups 1 and 2. Mean data obtained from rats studied before sodium chloride (group 1) or calcium chloride (group 2) infusion are summarized in Table I. The two groups of rats were similar with respect to body weight, kidney weight, and values for initial arterial Hct, initial $\mathrm{P}_{\mathrm{Ca}}$, and $\overline{\mathrm{AP}}$. The low values for Hct are the result of hypervolemic exchange transfusion. In groups 1 and $2, \overline{\mathrm{P}}_{\mathrm{GC}}$ averaged 47.2 $\pm 0.6 \mathrm{SEM}$ and $50.5 \pm 1.2 \mathrm{~mm} \mathrm{Hg}$, whereas mean values for $\mathrm{P}_{\mathrm{T}}$ were $12.2 \pm 0.3$ and $13.4 \pm 0.7 \mathrm{~mm} \mathrm{Hg}$, respectively. Therefore, the glomerular transcapillary hydraulic pressure difference, $\overline{\Delta P}$, averaged $35.0 \pm 0.7$ in group 1 and $37.1 \pm 1.3 \mathrm{~mm} \mathrm{Hg}$ in group 2. Values for $C_{A}$ and $\Pi_{A}$ were similar in the two groups, averaging $5.7 \pm 0.1 \mathrm{~g} / \mathrm{dl}$ and $19.0 \pm 0.5 \mathrm{~mm} \mathrm{Hg}$ in group $\mathrm{l}$ and $5.8 \pm 0.1 \mathrm{~g} / \mathrm{dl}$ and $19.9 \pm 0.7 \mathrm{~mm} \mathrm{Hg}$ in group 2 . Values for $C_{E}$ were slightly lower in group 1 , averaging 8.0 \pm 0.1 vs. $8.5 \pm 0.2 \mathrm{~g} / \mathrm{dl}$ in group 2 . SNFF averaged 0.28 \pm 0.02 in group 1 and $0.32 \pm 0.02$ in group 2 . Values for SNGFR and total kidney GFR were comparable in both groups (Table I).

Values for $\Pi_{E}$ (averaging $31.5 \pm 0.9$ in group 1 and $34.9 \pm 1.5 \mathrm{~mm} \mathrm{Hg}$ in group 2) were usually less than $\overline{\Delta \mathrm{P}}$ (on average, $35.0 \pm 0.7$ and $37.1 \pm 1.3 \mathrm{~mm} \mathrm{Hg}$, respectively), denoting failure to achieve filtration pressure equilibrium by the efferent-most portion of the glomerular capillary network. Filtration pressure disequilibrium occurred as a result of high values of $Q_{A}$ in both groups, averaging $168 \pm 20$ in group 1 and 146 $\pm 18 \mathrm{nl} / \mathrm{min}$ in group 2 . These high values for $Q_{A}$, approximately twice the typical normal hydropenic value for this strain of rats $(5,21-25)$, were the result of hypervolemic exchange transfusion. Indeed, values for the ratio $\Pi_{E} / \overline{\Delta P}$ of less than unity (on average, 0.91 \pm 0.02 in group 1 and $0.94 \pm 0.02$ in group 2 ) have been found to be the rule in a variety of similar high $Q_{A}$ states studied in this laboratory $(5,22,26,27)$. Because filtration equilibrium was not achieved, it was possible to calculate unique values for the glomerular capillary ultrafiltration coefficient, $K_{f} . K_{f}$ averaged $0.088 \pm 0.012$ 
TABLE I

Whole Animal and Single Nephron Data from Experimental Groups 1 and 2

\begin{tabular}{|c|c|c|c|c|c|c|c|c|c|c|c|c|c|c|c|c|c|}
\hline Condition & $\mathbf{B W}^{*}$ & $\mathbf{K W}$ & Het & $\mathbf{P}_{\mathrm{Ca}}$ & $\overline{\mathbf{A P}}$ & $\overline{\mathbf{P}}_{\mathrm{GC}}$ & $\mathbf{P}_{\mathbf{T}}$ & $\mathrm{C}_{\boldsymbol{A}}$ & $\mathbf{C}_{\mathbf{E}}$ & $\Pi_{\Lambda}$ & $\Pi_{\mathbf{E}}$ & $\Pi_{\mathbf{E}} / \overline{\Delta \mathbf{P}}$ & SNGFR & GFR & $\mathbf{Q}_{\mathbf{A}}$ & SNFF & $K_{f}$ \\
\hline & & $g$ & vol \% & $m g / d l$ & & $m m \mathbf{H g}$ & & g & & $m m$ & $\mathrm{Hg}$ & & $\begin{array}{c}n l / \\
\min \end{array}$ & $\begin{array}{c}m l / \\
\min \end{array}$ & $\begin{array}{c}n l / \\
\min \end{array}$ & & $\begin{array}{c}n l /(s . \\
m m H g)\end{array}$ \\
\hline \multicolumn{18}{|l|}{$\begin{array}{l}\text { Group } 1 \\
\quad(n=7 \text { rats })\end{array}$} \\
\hline \multirow[t]{2}{*}{ Non-TPTX } & 241 & 0.90 & 32.4 & 9.4 & 117 & 47.2 & 12.2 & 5.7 & 8.0 & 19.0 & 31.5 & 0.91 & 44.3 & 1.10 & 168 & 0.28 & 0.088 \\
\hline & \pm 11 & 0.06 & 0.8 & 0.2 & 4 & 0.6 & 0.3 & 0.1 & 0.1 & 0.5 & 0.9 & 0.02 & 4.2 & 0.06 & 20 & 0.02 & 0.012 \\
\hline \multirow[t]{2}{*}{$\mathrm{NaCl}$} & - & - & 27.7 & 8.8 & 111 & 49.6 & 15.0 & 5.5 & 7.8 & 17.9 & 30.4 & 0.92 & 50.2 & 1.17 & 194 & 0.29 & 0.096 \\
\hline & - & - & 1.3 & 0.1 & 3 & 0.8 & 0.9 & 0.2 & 0.2 & 0.7 & 1.5 & 0.03 & 2.7 & 0.09 & 33 & 0.03 & 0.015 \\
\hline$P \S$ & - & - & $<0.001$ & $<0.05$ & $<0.05$ & $<0.05$ & $<0.01$ & $>0.10$ & $>0.20$ & $>0.10$ & $>0.20$ & $>0.70$ & $<0.05$ & $>0.05$ & $>0.20$ & $>0.50$ & $>0.50$ \\
\hline \multicolumn{18}{|l|}{$\begin{array}{l}\text { Group } 2 \\
\quad(n=7 \text { rats })\end{array}$} \\
\hline \multirow[t]{2}{*}{ Non-TPTX } & 238 & 0.95 & 33.0 & 9.5 & 116 & 50.5 & 13.4 & 5.8 & 8.5 & 19.9 & 34.9 & 0.94 & 45.0 & 1.20 & 146 & 0.32 & 0.085 \\
\hline & \pm 6 & 0.02 & 0.8 & 0.2 & 4 & 1.2 & 0.7 & 0.1 & 0.2 & 0.7 & 1.5 & 0.02 & 4.5 & 0.11 & 18 & 0.02 & 0.008 \\
\hline \multirow[t]{2}{*}{$\mathrm{CaCl}_{2}$} & - & - & 26.8 & 13.2 & 115 & 50.8 & 14.0 & 5.2 & 7.1 & 16.3 & 26.1 & 0.71 & 31.4 & 0.85 & 124 & 0.27 & 0.035 \\
\hline & - & - & 2.0 & 0.5 & 6 & 1.1 & 0.9 & 0.1 & 0.2 & 0.6 & 1.2 & 0.03 & 2.6 & 0.09 & 15 & 0.02 & 0.003 \\
\hline$P \oint$ & - & - & $<0.05$ & $<0.02$ & $>0.70$ & $>0.70$ & $>0.60$ & $<0.01$ & $<0.01$ & $<0.05$ & $<0.01$ & $<0.001$ & $<0.02$ & $<0.05$ & $>0.05$ & $<0.01$ & $<0.01$ \\
\hline
\end{tabular}

Values are expressed as means $\pm 1 \mathrm{SE}$.

* Body weight.

\ Kidney weight.

$\$$ Calculated from paired data using Student's $t$ test.

in group 1 and $0.085 \pm 0.008 \mathrm{nl} /(\mathrm{s} \cdot \mathrm{mm} \mathrm{Hg})$ in group 2, similar to mean values obtained previously $(22,26)$.

Effects of calcium chloride and sodium chloride infusion. Mean values for these same quantities obtained after calcium chloride or sodium chloride infusion are also given in Table 1. With calcium chloride infusion, plasma calcium concentration rose significantly, on average by nearly $4 \mathrm{mg} / \mathrm{dl}$, from $9.5 \pm 0.2$ to $13.2 \pm 0.5 \mathrm{mg} / \mathrm{dl}(P<0.02)$ and fell slightly but significantly, with sodium chloride infusion. No change occurred in $\overline{\mathrm{AP}}$ in either group, whereas Hct fell significantly, due to the continuous plasma infusion. As seen for group 2 rats in Table I, whole kidney GFR and SNGFR declined by nearly $30 \%$, on average from $1.20 \pm 0.11$ and $45.0 \pm 4.5$ to $0.85 \pm 0.09 \mathrm{ml} / \mathrm{min}$ and 31.4 $\pm 2.6 \mathrm{nl} / \mathrm{min}$, respectively $(P<0.05, P<0.02)$, in contrast to the mild volume-expansion induced increases in whole kidney GFR and SNGFR measured in group 1 rats. Similarly, SNFF fell from a mean value of 0.32 \pm 0.02 to $0.27 \pm 0.02(P<0.01)$ after calcium chloride infusion but failed to change after sodium chloride.

The effects of acute hypercalcemia or sham treatment on the four determinants of GFR are also illustrated in Table $I$. $Q_{A}$ failed to change significantly in either group, rising slightly in group 1 (on average from 168 \pm 20 to $194 \pm 33 \mathrm{nl} / \mathrm{min}, P>0.20$ ) and declining slightly in group 2 (on average from $146 \pm 18$ to $124 \pm 15 \mathrm{nl} / \mathrm{min}$, $P>0.05)$. Likewise, little change in $\overline{\Delta P}$ occurred in either group, averaging $34.6 \pm 0.8$ and $36.8 \pm 1.2 \mathrm{~mm} \mathrm{Hg}$, for groups 1 and 2 , respectively. Values for $P_{C}$ averaged $11 \pm 0.8$ and $12 \pm 0.6 \mathrm{~mm} \mathrm{Hg}(P>0.40)$ in the two study periods in group 1 , and $12 \pm 1.1$ and $12 \pm 0.9(P>0.50)$ in the corresponding periods in group 2 rats. $\Pi_{A}$ declined modestly but significantly in group 2 , on average from $19.9 \pm 0.7$ to $16.3 \pm 0.6 \mathrm{~mm} \mathrm{Hg}(P<0.05)$, a consequence of the fall in $C_{A}$, on average from $5.8 \pm 0.1$ to $5.2 \pm 0.1 \mathrm{~g} / \mathrm{dl}(P<0.01)$. By contrast, there was no significant change in $C_{A}$ or $\Pi_{A}$ in the sodium chloridetreated group. Although this decline in $\Pi_{A}$ in the hypercalcemia group would have been expected to raise GFR and SNGFR slightly, these measures of filtration rate declined in group 2 because of a profound and significant decline in $K_{f}$, on average by nearly $60 \%$ (Table I), from a mean value of 0.085 \pm 0.008 to $0.035 \pm 0.003 \mathrm{nl} /(\mathrm{s} \cdot \mathrm{mm} \mathrm{Hg})(P<0.01)$. The ratio of $\Pi_{\mathrm{E}} / \overline{\Delta \mathrm{P}}$ declined in each rat with hypercalcemia (on average to $0.71 \pm 0.03$ ). These falls in $K_{f}$ and $\Pi_{E} / \overline{\Delta P}$ were not seen in the sodium chloridetreated group.

Effects of TPTX in groups 3 and 4. Whole animal and single nephron data from animals in groups 3 and 4 are summarized in Table II. Groups 3 and 4 were similar with respect to body and kidney weight, $\mathbf{H c t}, \mathbf{P}_{\mathrm{Ca}}$, and $\overline{\mathrm{AP}}$. During the initial study period, $\mathrm{FE}_{\mathrm{p}}$ averaged $0.9 \pm 0.6 \%$ in group 3 and $0.4 \pm 0.1 \%$ in group 4 , much less than the mean value of $7.7 \pm 1.5 \%$ obtained in nonTPTX rats by us previously (4), and indicating effective removal of functioning parathyroid tissue.

Once again, because of the hypervolemic exchange transfusion, high values of $Q_{A}$ were obtained, averaging $143 \pm 17 \mathrm{nl} / \mathrm{min}$ in group 3 and $141 \pm 14 \mathrm{nl} / \mathrm{min}$ in group 4. Values for $C_{A}$ and $\Pi_{A}$ were similar in these two groups. Values for $C_{E}$ were slightly higher in group 3, averaging $8.6 \pm 0.3 \mathrm{vs}$. $8.3 \pm 0.2 \mathrm{~g} / \mathrm{dl}$ in group 4 . As 
TABLE II

Whole Animal and Single Nephron Data from Experimental Groups 3 and 4

\begin{tabular}{|c|c|c|c|c|c|c|c|c|c|c|c|c|c|c|c|c|c|c|}
\hline Condition & BW* & KWt & Het & $\mathbf{F E}_{\mathrm{p}}$ & $\mathbf{P}_{\mathrm{ca}}$ & $\overline{\mathbf{A P}}$ & $\overline{\mathbf{P}_{\mathrm{CC}}}$ & $\mathbf{P}_{\mathbf{T}}$ & $\mathrm{C}_{\mathrm{A}}$ & $\mathrm{C}_{\mathrm{E}}$ & $\mathbf{I}_{\mathbf{A}}$ & $\Pi_{\mathbf{E}}$ & $\Pi_{\mathrm{E}} / \overline{\mathbf{\Delta P}}$ & SNGFR & GFR & $\mathbf{Q}_{\mathbf{A}}$ & SNFF & $K_{f}$ \\
\hline & & $g$ & vol \% & $\%$ & $m g / d l$ & & $m m \mathbf{H g}$ & & g & dl & $m m$ & $\mathrm{Hg}$ & & $\begin{array}{c}n l / \\
\min \end{array}$ & $\begin{array}{l}m l / \\
\min \end{array}$ & $\begin{array}{c}n l l \\
\min \end{array}$ & & $\begin{array}{c}n l l \\
(s \cdot m m \\
H g)\end{array}$ \\
\hline \multicolumn{19}{|l|}{$\begin{array}{l}\text { Group } 3 \\
\quad(n=7 \text { rats })\end{array}$} \\
\hline TPTX & 245 & 1.03 & 32.5 & 0.9 & 9.5 & 118 & 51.2 & 15.6 & 5.7 & 8.6 & 18.8 & 36.0 & 1.01 & 46.2 & 1.24 & 143 & 0.33 & $0.100 \$$ \\
\hline & \pm 8 & 0.08 & 0.8 & 0.6 & 0.3 & 1 & 1.8 & 0.8 & 0.1 & 0.3 & 0.7 & 2.0 & 0.02 & 4.7 & 0.11 & 17 & 0.02 & 0.011 \\
\hline TPTX and & - & - & 29.9 & 0.6 & 14.0 & 123 & 46.8 & 14.0 & 5.4 & 8.0 & 17.6 & 31.8 & 0.97 & 39.4 & 1.02 & 123 & 0.32 & $0.082 \S$ \\
\hline $\mathrm{CaCl}_{2}$ & - & - & 0.9 & 0.2 & 0.6 & 2 & 1.3 & 0.8 & 0.1 & 0.3 & 0.7 & 1.9 & 0.05 & 4.0 & 0.12 & 12 & 0.01 & 0.012 \\
\hline$P^{\prime \prime}$ & - & - & $<0.01$ & $>0.10$ & $<0.001$ & $>0.05$ & $<0.02$ & $>0.40$ & $<0.05$ & $>0.10$ & $<0.05$ & $>0.10$ & $>0.40$ & $>0.10$ & $>0.05$ & $>0.30$ & $>0.60$ & $>0.20$ \\
\hline \multicolumn{19}{|l|}{$\begin{array}{l}\text { Group } 4 \\
\quad(n=7 \text { rats })\end{array}$} \\
\hline \multirow[t]{2}{*}{ TPTX } & 243 & 1.01 & 31.9 & 0.4 & 9.5 & 121 & 49.7 & 16.4 & 5.5 & 8.3 & 17.9 & 33.6 & 1.01 & 46.2 & 1.26 & 141 & 0.34 & $0.101 \S$ \\
\hline & \pm 8 & 0.04 & 1.2 & 0.1 & 0.2 & 4 & 1.0 & 1.1 & 0.1 & 0.2 & 0.6 & 1.6 & 0.01 & 1.5 & 0.11 & 14 & 0.03 & 0.010 \\
\hline TPTX and & - & - & 29.1 & 2.5 & 13.2 & 115 & 52.5 & 15.2 & 5.4 & 8.2 & 17.6 & 33.2 & 0.89 & 33.2 & 0.89 & 100 & 0.34 & 0.048 \\
\hline $\begin{array}{l}\mathrm{CaCl}_{2} \\
\text { and PTH }\end{array}$ & - & - & 1.0 & 0.6 & 0.4 & 5 & 0.9 & 1.1 & 0.1 & 0.2 & 0.3 & 1.4 & 0.02 & 1.6 & 0.08 & 8 & 0.02 & 0.005 \\
\hline$P^{\prime \prime}$ & - & - & $<0.01$ & $<0.01$ & $<0.001$ & $>0.10$ & $<0.01$ & $<0.02$ & $>0.40$ & $>0.70$ & $>0.40$ & $>0.80$ & $<0.001$ & $<0.01$ & $<0.01$ & $<0.02$ & $>0.80$ & $<0.01$ \\
\hline
\end{tabular}

Values are expressed as means $\pm 1 \mathrm{SE}$.

* Body weight.

t Kidney weight.

$\$$ Denotes mean $\pm 1 \mathrm{SE}$ of the minimum $\mathrm{K}_{\mathrm{f}}$ value determined in each rat.

"Calculated from paired data using Student's $t$ test.

shown in Table II, values for GFR, SNGFR, and SNFF were similar, on average, in these groups.

$\overline{\mathrm{P}}_{\mathrm{GC}}$ averaged $51.2 \pm 1.8 \mathrm{~mm} \mathrm{Hg}$ in group 3 and 49.7 $\pm 1.0 \mathrm{~mm} \mathrm{Hg}$ in group 4. Mean values for $P_{T}$ were also similar, averaging $15.6 \pm 0.8$ and $16.4 \pm 1.1 \mathrm{~mm} \mathrm{Hg}$ in groups 3 and 4 , respectively. Accordingly, mean values for $\overline{\Delta P}$ were similar in each group. In both groups, values for $\Pi_{E}$ (averaging $36.0 \pm 2.0$ in group 3 and $33.6 \pm 1.6 \mathrm{~mm} \mathrm{Hg}$ in group 4) approximated those of $\overline{\Delta \mathrm{P}}$ (on average, $35.6 \pm 1.6$ in group 3 and $33.2 \pm 1.6 \mathrm{~mm}$ $\mathrm{Hg}$ in group 4), so that $\Pi_{\mathrm{E}} / \overline{\Delta \mathrm{P}}$ did not differ from unity (on average, $1.01 \pm 0.02$ in group 3 and $1.01 \pm 0.01$ in group 4). Therefore, filtration pressure equilibrium occurred in both groups of rats after TPTX. Given filtration pressure equilibrium in TPTX rats, only minimum values for $K_{f}$ can be calculated, for reasons discussed at length elsewhere (26). These minimum values averaged $0.100 \pm 0.011$ and $0.101 \pm 0.010 \mathrm{nl} /$ $(\mathrm{s} \cdot \mathrm{mm} \mathrm{Hg})$ in groups 3 and 4 , respectively, and are therefore higher than unique values obtained in the initial period of non-TPTX rats in groups 1 and 2. This tendency for $K_{f}$ to increase with acute PTH deficiency has recently been described (4).

Effects of calcium chloride infusion in TPTX rats (group 3). Whole animal and single nephron data obtained before and during calcium chloride infusion in TPTX rats are summarized in Table II. No significant change in $\overline{\mathrm{AP}}$ occurred with hypercalcemia (averaging $118 \pm 1$ vs. $123 \pm 2 \mathrm{~mm} \mathrm{Hg}, P>0.05$ ), but Hct fell significantly $(32.5 \pm 0.8$ to $29.9 \pm 0.9 \%, P<0.01)$ with the continuing plasma infusion. No change occurred in $\mathrm{FE}_{\mathrm{p}}$, averaging $0.9 \pm 0.6$ before and $0.6 \pm 0.2 \%$ during, calcium chloride infusion, implying continuing low levels of circulating PTH. $\mathrm{P}_{\mathrm{Ca}}$, however, rose significantly $(P<0.001$; on average from $9.5 \pm 0.3$ to 14.0 $\pm 0.6 \mathrm{mg} / \mathrm{dl}$ ). As seen in Table III, the levels of ultrafilterable serum calcium concentration were comparable in hypercalcemic rats from groups 2 and 3 ,

TABLE III

Total Plasma and Ultrafilterable Serum Calcium Concentrations during Experimental Study Period

\begin{tabular}{lcc}
\hline \multicolumn{1}{c}{ Condition } & $\begin{array}{c}\text { Total plasma } \\
\text { (calcium) }\end{array}$ & $\begin{array}{c}\text { Ultrafilterable } \\
\text { serum (calcium) }\end{array}$ \\
\hline & $m g / d l$ & $m g / d l$ \\
Non-TPTX $+\mathrm{NaCl}$ & & \\
Rat 29 & 9.2 & 5.6 \\
Rat 30 & 9.0 & 5.2 \\
Non-TPTX $+\mathrm{CaCl}_{2}$ & & \\
Rat 31 & 12.1 & 6.6 \\
Rat 32 & 13.7 & 7.3 \\
TPTX $+\mathrm{CaCl}_{2}$ & & 7.8 \\
Rat 33 & 14.5 & 7.6 \\
Rat 34 & 13.2 & 8.3 \\
TPTX $+\mathrm{CaCl}_{2}+$ PTH & & 7.3 \\
Rat 35 & 15.1 & \\
Rat 36 & 12.7 & \\
\hline
\end{tabular}


and consistently in excess of levels obtained in nonhypercalcemic group 1 control rats.

After calcium chloride infusion in TPTX rats, $Q_{A}$ fell slightly, from a mean value of $143 \pm 17$ to $123 \pm 12$ $\mathrm{nl} / \mathrm{min}(P>0.30)$. As with total kidney GFR, SNGFR did not change significantly with hypercalcemia in TPTX rats (Table II). Consequently, SNFF was similar in both study periods in group 3 rats, averaging $0.33 \pm 0.02$ before and $0.32 \pm 0.01(P>0.60)$ during, calcium chloride infusion.

During calcium chloride infusion in TPTX rats, $\overline{\mathbf{P}}_{\mathrm{GC}}$ declined significantly $(P<0.02)$ from a mean value of $51.2 \pm 1.8$ to $46.8 \pm 1.3 \mathrm{~mm} \mathrm{Hg}$, whereas $P_{\mathrm{T}}$ was largely unchanged, averaging $15.6 \pm 0.8$ before and $14.0 \pm 0.8$ $\mathrm{mm} \mathrm{Hg}$ during, calcium chloride infusion $(P>0.40)$. Therefore, values for $\overline{\Delta \mathrm{P}}$ fell significantly during hypercalcemia, on average from $35.6 \pm 1.6$ to $32.8 \pm 0.8$ $\mathrm{mm} \mathrm{Hg}(P<0.02)$. Values for $P_{c}$ were unchanged by calcium chloride infusion, averaging $10 \pm 1.0$ and 10 $\pm 1.2 \mathrm{~mm} \mathrm{Hg}(P>0.50)$ in the two study periods in this group. Average values for $C_{E}$ and $\Pi_{E}$ decreased moderately with calcium chloride in group 3 (from 8.6 \pm 0.3 to $8.0 \pm 0.3 \mathrm{~g} / \mathrm{dl}, P>0.10$, and $36.0 \pm 2.0$ to 31.8 $\pm 1.9 \mathrm{~mm} \mathrm{Hg}, P>0.10$ ). Thus, as in the initial period, the ratio of $\Pi_{\mathrm{E}} / \overline{\Delta \mathrm{P}}$ remained close to unity, averaging $0.97 \pm 0.05$. Once again, only minimum values for $K_{f}$ could be calculated under these conditions. These minimum values for $K_{f}$ in hypercalcemic TPTX rats were, on average, similar to initial values (Table II).

Effects of calcium chloride and PTH infusion in TPTX rats (Group 4). Average values for whole animal and single nephron data in group 4 are summarized in Table II. As with group 3 rats, Hct fell significantly, $\overline{\mathrm{AP}}$ remained largely unchanged, and $\mathrm{P}_{\mathrm{Ca}}$ rose significantly with calcium chloride and PTH infusions, the latter from a mean value of $9.5 \pm 0.2$ to $13.2 \pm 0.4 \mathrm{mg} / \mathrm{dl}$. As shown in Table III, ultrafilterable serum calcium concentrations were similar to values obtained in groups 2 and 3. With the PTH infusion, $\mathrm{FE}_{\mathrm{p}}$ rose in each animal, from an average value of $0.4 \pm 0.1$ to 2.5 $\pm 0.6 \%(P<0.01)$.

After administration of PTH and calcium chloride, $Q_{A}$ fell significantly, from a mean value of $141 \pm 14$ to $100 \pm 8 \mathrm{nl} / \mathrm{min}(p<0.02)$. As with total kidney GFR, SNGFR decreased significantly in group 4 (on average from $1.26 \pm 0.11$ and $46.2 \pm 1.5$ to $0.89 \pm 0.08 \mathrm{ml} / \mathrm{min}$ and $33.2 \pm 1.6 \mathrm{nl} / \mathrm{min}$, respectively), whereas $\mathrm{SNFF}$ was identical in both periods. $C_{A}$ and $\Pi_{A}$ showed little change, averaging $5.5 \pm 0.1$ and $17.9 \pm 0.6$ before and 5.4 $\pm 0.1 \mathrm{~g} / \mathrm{dl}$ and $17.6 \pm 0.3 \mathrm{~mm} \mathrm{Hg}$ after, combined PTH and calcium chloride infusion.

$\overline{\mathbf{P}}_{\mathrm{GC}}$ increased significantly with calcium chloride and PTH infusion, from an initial mean value of $49.7 \pm 1.0$ to $52.5 \pm 0.9 \mathrm{~mm} \mathrm{Hg}(P<0.01)$. Concomitantly, $\mathrm{P}_{\mathrm{T}}$ fell slightly, on average from $16.4 \pm 1.1$ to $15.2 \pm 1.1 \mathrm{~mm} \mathrm{Hg}$, $(P<0.02)$. Therefore, $\overline{\Delta \mathrm{P}}$ rose substantially, on average from $33.9 \pm 1.6$ to $38.9 \pm 1.2 \mathrm{~mm} \mathrm{Hg},(P<0.01)$. Values for $P_{C}$ averaged $12 \pm 1.1$ and $11 \pm 0.9 \mathrm{~mm} \mathrm{Hg}(P>0.40)$ before and during calcium chloride-PTH infusion, respectively. Average values for $C_{E}$ and $\Pi_{E}$ were similar in both periods (Table II). With calcium chloride and PTH infusions, values of $\Pi_{E}$ were always lower than $\overline{\Delta \mathrm{P}}$, the ratio $\Pi_{\mathrm{E}} / \overline{\Delta \mathrm{P}}$ averaging $0.89 \pm 0.02$, a value significantly less than unity $(P<0.001)$. Thus, unique values for $K_{f}$ could be calculated and averaged 0.048 $\pm 0.005 \mathrm{nl} /(\mathrm{s} \cdot \mathrm{mm} \mathrm{Hg})$, considerably lower $(P<0.01)$ than that obtained in the initial period (Table II).

\section{DISCUSSION}

It is well known that hypercalcemia leads to a decrease in GFR, both acutely $(11,12)$ and chronically $(13)$. Before this study, the mechanism(s) responsible for this decline in GFR had not been elucidated. Changes in any of the four determinants of GFR, i.e., a decrease in $\mathrm{Q}_{\mathrm{A}}, \overline{\Delta \mathrm{P}}$, or $K_{f}$, or a rise in $\mathrm{C}_{\mathrm{A}}$, or any combination thereof, can bring about a reduction in GFR. It has been assumed that the primary basis for a decline in GFR with hypercalcemia is a fall in renal plasma flow (28). In group 2 rats, whereas the fall in $Q_{A}$ was, on average, about $15 \%$ with hypercalcemia, the declines in GFR and SNGFR averaged some $30 \%$. By using the model of Deen et al. (15), we calculate that this fall in $Q_{A}$ accounts for slightly less than one-third of the total reduction in SNGFR. Because $\overline{\mathrm{AP}}$ changed little, if at all, with hypercalcemia, this lesser decline in $Q_{A}$ than SNGFR was the consequence of near-constancy of renal arteriolar resistances. Thus, calcium chloride infusion led to mild, but insignificant, increases in afferent arteriolar $\left(R_{A}\right)$, efferent arteriolar $\left(R_{E}\right)$ and total arteriolar resistances $R_{T A}$ ), in non-TPTX rats (group 2), $R_{A}$ increasing from $2.7 \pm 0.4$ to $3.4 \pm 0.7 \times 10^{10} \mathrm{dyn} \cdot \mathrm{s} \cdot \mathrm{cm}^{-5}$ $(P>0.10), R_{E}$ from $1.9 \pm 0.3$ to $2.5 \pm 0.4(P>0.05)$, and $R_{T A}$ from $4.6 \pm 0.7$ to $5.9 \pm 1.1(P>0.05)$. Similarly, values for $\overline{\Delta P}$ were essentially unchanged by calcium chloride infusions, eliminating this possible factor in bringing about the observed reductions in filtration rate. Values for $\mathrm{C}_{\mathrm{A}}$ declined slightly, on average, during hypercalcemia in group 2 rats. We have shown previously (27) that a decline in $\mathrm{C}_{\mathrm{A}}$ of the magnitude observed in the present study leads to an increase, rather than a decrease, in GFR. Therefore, the major factor responsible for the declines in GFR and SNGFR measured during acute hypercalcemia in non-TPTX rats was a profound reduction in $K_{f}$. This decline in $K_{f}$, on average to some $40 \%$ of the precalcium infusion value, was not seen in rats infused with sodium chloride (group 1). This decrease in $K_{f}$ therefore constitutes the primary mechanism by which acute hypercalcemia leads to reduced GFR.

Recent findings by Dousa and co-workers (2) indicate that PTH-dependent cyclic nucleotide production in 
renal tubule epithelial cells is enhanced by addition of calcium ions to the incubation medium. Even though circulating levels of PTH would be expected to fall with acute hypercalcemia, these findings by Dousa and co-workers raise the possibility that some PTH (circulating or in some other manner made available to the glomerular cells) may also be necessary to elicit the hypercalcemia-related declines in $K_{f}$ and GFR. Therefore, a separate group of acute TPTX rats (group 3) was studied before and during acute hypercalcemia. Effective removal of functioning parathyroid tissue in this group of rats was verified by the finding of very low values for $\mathrm{FE}_{\mathrm{p}}$, averaging $0.9 \pm 0.6 \%$. The rise in $P_{C a}$ and in ultrafilterable serum calcium concentration induced by calcium chloride infusion was similar in group 3 rats to values obtained in non-TPTX group 2 rats. As shown in Table II, whereas acute hypercalcemia led to $\sim 30 \%$ average declines in GFR and SNGFR in group 2 rats, equivalent elevation in serum calcium concentration in the TPTX group failed to alter GFR or SNGFR significantly. This failure for filtration rate to decline significantly with hypercalcemia in the TPTX group was due largely to failure of $K_{f}$ to decline to values sufficiently low to prevent achievement of filtration pressure equilibrium, and hence to reach values low enough to influence SNGFR.

To ascertain whether this failure for $K_{f}$ to decline below the normal range with acute hypercalcemia in TPTX rats was the consequence of deficiency of PTH per se (rather than to TPTX-induced loss of calcitonin and/or thyroid hormones), a submaximally phosphaturic dose of synthetic bovine PTH was infused into an additional group of seven TPTX rats (group 4) also made hypercalcemic. Each rat displayed a PTHrelated rise in $\mathrm{FE}_{\mathrm{p}}$. The mean changes in SNGFR and $K_{f}$ during PTH and calcium chloride infusion in group 4 rats are depicted in Fig. 1. For comparison, the mean changes in these quantities induced by hypercalcemia in non-TPTX rats (group 2) and in TPTX rats (group 3) are also shown. The combined infusion of calcium chloride and a small dose of PTH had the effect of reproducing nearly exactly the striking declines in SNGFR and $K_{f}$ noted in non-TPTX rats given calcium chloride alone. In order words, when PTH as well as calcium chloride are infused into TPTX rats, the changes in SNGFR and $K_{f}$ are indistinguishable from those seen in hypercalcemic rats with intact parathyroid glands. Of importance is the fact that these low doses of PTH, when given without calcium chloride, fail to lower $K_{f}$ below the normal range (4).

On average, the change in SNGFR (and total GFR) in group 4 rats after the combined calcium chloride-PTH infusion was proportional to the average change in $Q_{A}$. The decline in $Q_{A}$ cannot be taken to account entirely for the total measured decrement in SNGFR, however, for the following reasons. By using the model of Deen et al.

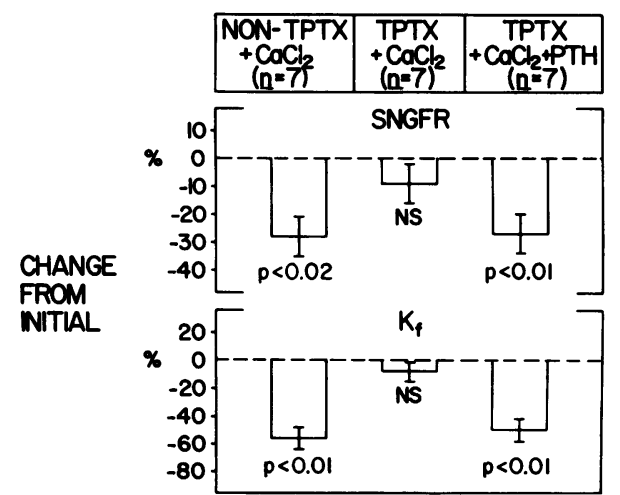

FIGURE 1 Comparison of changes in SNGFR and $K_{f}$ in non-TPTX rats receiving infusion of calcium chloride (left), TPTX rats receiving infusion of calcium chloride alone (center), and TPTX rats receiving infusions of calcium chloride and PTH (right). Results are shown as changes from initial or preinfusion values (mean \pm 1 SEM) for the quantities shown.

(15), we calculate that because the rats were at filtration disequilibrium during the combined calcium-PTH infusion, the change in SNGFR attributable to this fall in $Q_{A}$ is only $7 \mathrm{nl} / \mathrm{min}$. The concomitant fall in $K_{f}$ contributes a predicted decrease of about $13 \mathrm{nl} / \mathrm{min}$ to the total fall in SNGFR. The additive effects of these decreases in $Q_{A}$ and in $K_{f}$ exceed the observed $13 \mathrm{nl} / \mathrm{min}$ total decrement in SNGFR because of the concomitant rise in $\overline{\Delta P}$, which tends to raise SNGFR. Thus, the decline in $K_{f}$ represents the major factor responsible for the decline in SNGFR in group 4, a conclusion similar to that noted above for group 2 rats as well.

It is of obvious interest to define the mechanism(s) responsible for the PTH-dependent changes in $K_{f}$ seen in the present study in response to acute hypercalcemia. Other divalent cations, including uranyl and mercuric ions $(29,30)$, cause striking declines in GFR. Indeed, the uranyl ion has been shown to reduce $K_{f}$ substantially (29). That the decline in $K_{f}$, and thus SNGFR, induced by hypercalcemia is not a nonspecific effect of divalent cations is suggested by the finding in the present study that these changes in response to calcium chloride infusion are not observed when PTH is absent.

In considering alternative mechanisms, it is important to recall that the ultrafiltration coefficient, $K_{f}$, is best expressed in terms of its component quantities, namely, total glomerular capillary surface area (S) and the effective capillary hydraulic permeability $(k)$, i.e., $K_{f}=\mathrm{k} \cdot \mathrm{S}$.

With regard to capillary surface area (S), PTH is known to facilitate calcium ion movement from extracellular to intracellular cytosolic compartments (31). A rise in cytosolic calcium concentration is thought to be important in the generation of cGMP, inasmuch as the 
production of this cyclic nucleotide can be stimulated by calcium ion in several tissues, including renal epithelia $(9,10)$. Of related interest, Dousa and coworkers have recently found that PTH activates cGMP production in glomerular mesangial cells (2). Because these mesangial cells contain bundles of contractile myofilaments (32), and because smooth muscle is normally rich in cGMP (9), it is possible that cGMP is involved in stimulating mesangial contractility, the effect of which would be to decrease glomerular capillary surface area, $\mathrm{S}$, and hence $K_{f}$.

A decline in $K_{f}$ may also occur as a result of a fall in effective capillary water permeability, $\mathrm{k}$. ADH, $\mathrm{PTH}$, and $\mathrm{PGE}_{1}$, hormones known to reduce $K_{f}(3-5)$, are also capable of stimulating cAMP in isolated glomeruli $(1,2)$. Of interest is the fact that, in response to PTH at least, cAMP production in isolated glomeruli is confined almost exclusively to the visceral epithelial cells located on the urinary surface of the glomerular capillary wall (2), the surface currently believed largely responsible for modulating water permeability for these capillaries.

Clearly, additional studies are required to broaden our understanding of the mechanisms whereby calcium ions, PTH, and cyclic nucleotides interact to bring about these fascinating and previously unsuspected influences on the glomerular filtration process.

\section{ACKNOWLEDGMENTS}

The authors are grateful to Dr. Claude Lechene for measurement of ultrafilterable serum calcium concentrations, to $\mathrm{Mr}$. Wayne Willis and Ms. Alice Anderson for capable technical assistance, and to Ms. Lee Riley and Mrs. Debra Bohrer for expert secretarial assistance.

These studies were supported largely by grants from the U.S. Public Health Service (AM-19467 and AM-16105).

\section{REFERENCES}

1. Imbert, M., D. Chabardès, and F. Morel. 1974. Hormonesensitive adenylate-cyclase in isolated rabbit glomeruli. Mol. Cell. Endocrinol. 1: 295-304.

2. Dousa, T. P., L. D. Barnes, S. H. Ong, and A. L. Steiner. 1977. Immunocytochemical localization of $3^{\prime}, 5^{\prime}-$ cyclic AMP and $3^{\prime}, 5^{\prime}$-cyclic GMP in rat renal cortex: the effect of parathyroid hormone. Proc. Natl. Acad. Sci. U. S. A. 74: 3569-3573.

3. Ichikawa, I., and B. M. Brenner. 1977. Evidence for glomerular actions of ADH and dibutyryl cyclic AMP in the rat. Am. J. Physiol. 233:F102-F117.

4. Ichikawa, I., H. D. Humes, and B. M. Brenner. 1977. Evidence for a glomerular action of parathormone (PTH) in the rat. Trans. Assoc. Am. Physicians. In press.

5. Baylis, C., W. M. Deen, B. D. Myers, and B. M. Brenner. 1976. Effects of some vasodilator drugs on transcapillary fluid exchange in the renal cortex. Am. J. Physiol. 230: 1148-1158.

6. Rasmussen, H., K. Kurokawa, J. Mason, and D. B. P. Goodman. 1972. Cyclic AMP, calcium and cell activation. In
Calcium, Parathyroid Hormone, and the Calcitonins. R. V. Talmage and P. L. Munson, editors. Excerpta Medica, Amsterdam.

7. Nagata, N., and H. Rasmussen. 1970. Parathyroid hormone, $3^{\prime}, 5^{\prime}$-AMP, $\mathrm{Ca}^{++}$, and renal gluconeogenesis. Proc. Natl. Acad. Sci. U. S. A. 65: 368-374.

8. Nagata, N., and H. Rasmussen. 1970. Renal gluconeogenesis: effects of $\mathrm{Ca}^{++}$and $\mathrm{H}^{+}$. Biochim. Biophys. Acta. 215: 1-16.

9. Schultz, G., J. G. Hardman, K. Schultz, C. E. Baird, and E. W. Sutherland. 1973. The importance of calcium ions for the regulation of guanosine $3^{\prime}: 5^{\prime}$-cyclic monophosphate levels. Proc. Natl. Acad. Sci. U. S. A. 70: 3889-3893.

10. Criss, W. E., F. Murad, and H. Kimura. 1976. Properties of guanylate cyclase from rat kidney cortex and transplantable kidney tumors. J. Cyclic Nucleotide Res. 2: 11-19.

11. Edwards, B. R., R. A. L. Sutton, and J. H. Dirks. 1974. Effect of calcium infusions on renal tubular reabsorption in the dog. Am. J. Physiol. 227: 13-18.

12. Vanherweghem, J. L., J. Ducobu, A. D'Hollander, and C. Toussaint. 1976. Effects of hypercalcemia on water and sodium excretion by the isolated dog kidney. Pflügers Arch. Eur. J. Physiol. 363: 75-80.

13. Bennett, C. M. 1970. Urine concentration and dilution in hypokalemic and hypercalcemic dogs. J. Clin. Invest. 49: $1447-1457$.

14. Brenner, B. M., K. H. Falchuk, R. I. Keimowitz, and R. W. Berliner. 1969. Relationship between peritubular capillary protein concentration and fluid reabsorption by the renal proximal tubule. J. Clin. Invest. 48: 1519-1531.

15. Deen, W. M., C. R. Robertson, and B. M. Brenner. 1972. A model of glomerular ultrafiltration in the rat. Am. J. Physiol. 233: 1178-1183.

16. Habener, J. F., and J. T. Potts, Jr. 1976. Chemistry, biosynthesis, secretion, and metabolism of parathyroid hormone. Handb. Physiol. 7: 313-342.

17. Vurek, G. G., and S. E. Pegram. 1966. Fluorometric method for the determination of nanogram quantities of inulin. Anal. Biochem. 16: 409-419.

18. Führ, J., J. Kazmarczyk, and C. D. Krüttgen. 1955. Eine einfache colorimetrische Methode zur Inulinbestimmung für Nieren-Clearance-Untersuchungen bei Stoffwechselgesunden und Diabetikern. Klin. Wochenschr. 33: 729-730.

19. Lowry, O. H., N. J. Rosebrough, A. L. Farr, and R. J. Randall. 1951. Protein measurement with the Folin phenol reagent. J. Biol. Chem. 193: 265-275.

20. Deslsal, J. L., and H. Manhouri. 1958. Étude comparative des dosages colorimétriques du phosphate. IV. Dosage de l'orthophosphate en présence d'esters phosphoriques. Bull. Soc. Chim. Biol. 40: 1623-1636.

21. Brenner, B. M., J. L. Troy, and T. M. Daugharty. 1971. The dynamics of glomerular ultrafiltration in the rat. $J$. Clin. Invest. 50: 1776-1780.

22. Brenner, B. M., J. L. Troy, T. M. Daugharty, W. M. Deen, and C. R. Robertson. 1972. Dynamics of glomerular ultrafiltration in the rat. II. Plasma-flow dependence in GFR. Am. J. Physiol. 223: 1184-1190.

23. Blantz, R. C. 1974. Effect of mannitol on glomerular ultrafiltration in the hydropenic rat. J. Clin. Invest. 54: 1135-1143.

24. Blantz, R. C., K. S. Konnen, and B. J. Tucker. 1975. Glomerular filtration response to elevated ureteral pressure in both the hydropenic and the plasma-expanded rat. Circ. Res. 37: 819-829.

25. Maddox, D. A., C. M. Bennet, W. M. Deen, R. J. Glassock, 
D. Knutson, T. M. Daugharty, and B. M. Brenner. 1975. Determinants of glomerular filtration in experimental glomerulonephritis in the rat. J. Clin. Invest. 55: 305-318.

26. Deen, W. M., J. L. Troy, C. R. Robertson, and B. M. Brenner. 1973. Dynamics of glomerular ultrafiltration in the rat. IV. Determination of the ultrafiltration coefficient. J. Clin. Invest. 52: 1500-1508.

27. Baylis, C., I. Ichikawa, W. T. Willis, C. B. Wilson, and B. M. Brenner. 1977. Dynamics of glomerular ultrafiltration. IX. Effects of plasma protein concentration. Am. J. Physiol. 232: F58-F71.
28. Epstein, F. H. 1968. Calcium and the kidney. Am. J. Med. 45: 700-714.

29. Blantz, R. C. 1975. The mechanism of acute renal failure after uranyl nitrate. J. Clin. Invest. 55: 621-635.

30. Flanigan, W. J., and D. E. Oken. 1965. Renal micropuncture study of the development of anuria in the rat with mercury-induced acute renal failure. J. Clin. Invest. 44: 449-457.

31. Borle, A. B. 1973. Calcium metabolism at the cellular level. Fed. Proc. 32: 1944-1950.

32. Latta, H. 1973. Ultrastructure of the glomerulus and juxtaglomerular apparatus. Handb. Physiol. 8: 16. 